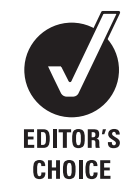

$10.1136 /$ ebn 1158

Centre for Research in Primary and Community Care, University of Hertfordshire, Hertfordshire, UK

Correspondence to: Claire Goodman

Centre for Research in Primary and Community Care, University of Hertfordshire, Hertfordshire AL10 9AB, UK;

c.goodman@herts.ac.uk

Cross-sectional study

\title{
The organisational culture of nursing staff providing long-term dementia care is related to quality of care
}

\section{Claire Goodman}

Commentary on: van Beek AP, Gerritsen DL. The relationship between organizational culture of nursing staff and quality of care for residents with dementia: questionnaire surveys and systematic observations in nursing homes. Int J Nurs Stud 2010;47:1274-82.

\section{Implications for nursing practice}

- Structured approaches that enable nursing staff to consider the culture of care they work within are likely to support reflection, critical discussion and improved quality of care.

- The physical and psychosocial care environment, characteristics of the nursing work and nursing staff, influence the well-being of people with dementia.

\section{Implications for research}

- Understanding how organisational culture can influence the quality of care is an important topic for nursing research.

- How the culture of care affects residents' quality of life and health outcomes needs further research.
- Intervention studies in care homes need to consider how to assess organisational context and culture and how different cultural contexts influence outcomes.

\section{Context}

As the population ages and more people require longterm care, how the culture of a nursing home influences care is an important question. The values and beliefs of practitioners have been repeatedly identified as, and linked to, how person-centred care for people with dementia is defined, understood and provided. ${ }^{1-3}$ This study uses the Competing Values Framework of Organisational Culture to investigate the relationship between organisational culture and quality of care in dementia units and nursing homes in The Netherlands. 


\section{Methods}

The authors describe the study as a cross-sectional design that involved a questionnaire-based survey of nursing staff and observations of care in nursing homes. Eleven dementia units in 11 nursing homes in The Netherlands took part in the study. Data collection involved questionnaires that used an adapted version of the Competing Values Framework to ask nursing staff to rate their workplace and the perceived quality of care. There were also interviews with unit supervisors and 2 days of observation on each unit.

Nurse participants were asked to rank the quality of care and allocate scores to response options that reflected a culture type. Observation involved a member of the research team and an employee of the nursing home using a 32-item observation list to record and rank different aspects of the residents' care. Observations were completed three times a day for 2 days.

Analysis was described as multilevel. It aimed to correlate the data for the observed and perceived quality of care with the culture scores of the 11 participating units.

\section{Findings}

A total of 248 participants (average response rate of 63\% per unit) completed the questionnaire. There was wide variation in the number of nurses employed across the 11 units. The majority of nurses believed the quality of care provided was 'good to very good'. The tasks most frequently identified as the nurses' main focus were delivering personal individual care, creating a nice and friendly atmosphere and providing residents with emotional support.

Perceived and observed quality of care were positively correlated, and the authors argue that the findings suggest nursing staff base their judgement of quality of care on what they perceive to be their task priorities. Where a unit was characterised as having a clan culture (as opposed to, eg, a market culture), this was positively correlated with perceived and observed quality of care.

\section{Commentary}

Studies in care homes consistently identify that how people with dementia are cared for reflect the priorities and values of the organisation. ${ }^{45}$ However, there is little work that has tried to establish a link between culture and the quality and outcomes of care. The authors are to be congratulated for taking a systematic approach and linking this work with a wider theoretical literature on organisational culture. It is interesting, however, that the authors in this study did not reference care-home-based work on the culture of care, for example, the nursing home culture change movement or the work that has been done on quality of life (as opposed to quality of care) for people living in long-term care. ${ }^{67}$ Nor is there reference to care-home-based studies that have focused on what older people consider to be important in their care and how person-centred care is defined and achieved in longterm care settings. ${ }^{8}$

The questionnaire on organisational culture was adapted for this study and offered participants rather stark choices in how they could describe their place of work. It is likely that a questionnaire that allowed more nuanced responses about quality and approaches to care delivery would have provided richer insights and still been able to highlight elements of hierarchy and market values as well as clan culture within the care home organisation.

The study relies heavily on practitioner perception and is a snapshot of care provision. It is unclear why the observation included employees as observers. The absence of the residents' experience or evidence from routinely collected data is a weakness of the study. Overall, although the study drew on a validated framework of assessment, the significance of its findings should be interpreted with caution. The study findings need to be linked to particular resident-specific outcomes.

\section{Competing interests None.}

\section{References}

1. Downs M. The emergence of the person in dementia research. Ageing Soc 1997;17:597-607.

2. Brooker D. Person-Centred Dementia Care: Making Services Better. London: Jessica Kingsley Publishers 2007.

3. Clare L, Rowlands J, Bruce E, et al. The experience of living with dementia in residential care: an interpretative phenomenological analysis. Gerontologist 2008;48:711-20.

4. Fossey J, Ballard C, Juszczak E, et al. Effect of enhanced psychosocial care on antipsychotic use in nursing home residents with severe dementia: cluster randomised trial. BMJ 2006;332:756-61.

5. Edvardsson D, Innes A. Measuring person-centered care: a critical comparative review of published tools. Gerontologist 2010;50:834-46.

6. Kane RA, Kling KC, Bershadsky B, et al. Quality of life measures for nursing home residents. J Gerontol A Biol Sci Med Sci 2003;58:240-8.

7. Stone R, Reinhard SC, Bowers B, et al. Evaluation of the Wellspring Model for Improving NH Quality. New York, NY: Commonwealth Fund, 2002.

8. Kitwood T. Dementia Reconsidered: The Person Comes First. Buckingham: Open University Press 1997. 